\title{
OS NANOMATERIAIS E A QUESTÃO AMBIENTAL
}

\author{
Matheus P. Paschoalino, Glauciene P. S. Marcone e Wilson F. Jardim* \\ Instituto de Química, Universidade Estadual de Campinas, CP 6154, 13083-970 Campinas - SP, Brasil
}

Recebido em 16/1/09; aceito em 3/8/09; publicado na web em 21/1/10

\begin{abstract}
NANOMATERIALS AND THE ENVIRONMENT. The increasing use of nanomaterials in several products in different areas such as electronics, cosmetics, food and drugs has attracted the attention of the scientific community due to unknown properties of these materials, such as the life cycle and the interaction with receptor organisms once they reach the environment. In this context, the present work shows an updated scenario of nanomaterials applications, characterization methods and toxicity evaluation, also addressing important aspects related to the development and application of nanotechnology under the environmental point of view.
\end{abstract}

Keywords: nanotechnology; environmental chemistry; toxicity.

\section{INTRODUÇÃO}

Nanociência e Nanotecnologia $(\mathrm{N} \& \mathrm{~N})$ envolvem processos, materiais e produtos na escala que varia entre 1 e 100 nanômetros e têm beneficiado distintos segmentos, tais como, alimentício, eletrônico, farmacêutico, biotecnológico, cosmético, médico-hospitalar, agrícola e de segurança nacional. ${ }^{1-4}$

Indubitavelmente, a nanotecnologia é um dos ramos da ciência que mais se desenvolve atualmente, fruto dos altos investimentos em pesquisa, sendo os maiores investidores os Estados Unidos, seguidos da Alemanha e Japão, enquanto que o Brasil integra o grupo no qual se encontram China e Índia. $\mathrm{O}$ crescimento da demanda por investimento em pesquisa nesta área pode ser ilustrado pelo significativo aumento das verbas destinadas pelo governo norte-americano que, em 2001, disponibilizava recursos da ordem de US\$ 464 milhões e, em 2007, investiu cerca de US\$ 1,5 bilhões. ${ }^{5}$ O Brasil, nos últimos anos, com recursos do plano plurianual (PPA 2004-2007) investiu cerca de R $\$ 140$ milhões. ${ }^{6}$

$\mathrm{O}$ crescente investimento em N\&N impulsiona o mercado mundial e potencializa o consumo de materiais, produtos e processos voltados para esta área. Contudo, observa-se que do montante destinado a este tipo de pesquisa, é escassa a quantia empregada em estudos de avaliação da toxicidade dos nanomateriais, exemplificado aqui pelos EUA, que do total investido em N\&N no ano de 2007 , apenas $3 \%$ foram destinados a estudos de avaliação de risco dos mesmos. ${ }^{5}$ Uma aparente exceção a esta tendência é a União Europeia, visto que o seu investimento para os próximos anos ( $£ 3,5$ bilhões) contempla amplamente as pesquisas voltadas para a avaliação da toxicidade e ecotoxicidade de nanomateriais e questões de segurança em geral. ${ }^{7}$

A produção anual estimada de materiais que contêm substâncias em nanoescala saltou de 1.000 toneladas em 2004 para 5.000 atualmente, com a perspectiva de que a marca de 100.000 toneladas seja atingida na próxima década. Estes números indicam a inevitável exposição humana e ambiental aos nanomateriais já presentes em cerâmicas, catalisadores, filmes e ligas metálicas, além do uso na indústria de cosméticos, nanoeletrônica, biotecnologia, instrumentação, sensores e na área ambiental. ${ }^{8}$

A crescente produção e aplicação de nanomateriais tem provocado a ampla discussão sobre os riscos potenciais destes materiais ao ambiente e à saúde humana. ${ }^{9}$ A reflexão a respeito desta questão é bastante pertinente, uma vez que, além das inúmeras perspectivas

*e-mail: wfjardim@iqm.unicamp.br oriundas do desenvolvimento de uma gama de novos materiais, há o potencial risco de contaminação ambiental, dadas as características intrínsecas das nanopartículas, como tamanho, área superficial e capacidade de aglomeração/dispersão, as quais podem facilitar a translocação destas pelos compartimentos ambientais e ocasionar, de forma acumulativa, danos à cadeia alimentar. Estes aspectos justificam a importância da investigação sobre a disponibilidade, degradabilidade e toxicidade dos nanomateriais. ${ }^{10}$

Estudos direcionados a tais questões constituem uma necessidade real. Contudo, a escassez e a desproporcionalidade de investimentos para avaliar a toxicidade dos nanomateriais são refletidas no número de trabalhos científicos publicados sobre o assunto. Dentre os 73.138 artigos publicados que apresentavam os tópicos nanotecnologia, nanomateriais ou nanopartículas, apenas 1.230 abordavam a questão da toxicidade e ecotoxicidade dos mesmos. ${ }^{11,12}$

Dentro deste contexto, a presente revisão aborda o conhecimento atual sobre a interação dos nanomateriais com os diferentes receptores ambientais, as técnicas de caracterização fundamentais mais utilizadas para investigar a correlação com os possíveis efeitos tóxicos, a tendência dos métodos aplicados na avaliação toxicológica e ecotoxicológica, finalizando com a discussão atual sobre a regulamentação e padronização que envolve a manufatura e o uso dos materiais e produtos baseados na nanotecnologia.

\section{INTERAÇÕES DOS NANOMATERIAIS NO AMBIENTE}

Diferentes tipos de nanomateriais estão sendo descobertos a cada dia e, por viabilizarem produtos finais mais eficientes, leves, adequados e principalmente de baixo custo, muitos destes se encontram em fase de comercialização em cosméticos, eletrodomésticos, vestimentas e em diversos utensílios e equipamentos. ${ }^{13}$ Contudo, as mesmas propriedades que tornam os nanomateriais tão atrativos, como pequeno tamanho de partícula, forma variada e alta área superficial, ${ }^{3,14}$ podem também ser responsáveis por efeitos nocivos aos organismos vivos, ${ }^{15}$ conforme indícios reportados por estudos toxicológicos com micro-organismos, algas, peixes, ratos e células humanas. ${ }^{16-20}$

A preocupação com relação à toxicidade das nanopartículas reside principalmente no fato de que estas nunca foram produzidas e utilizadas em produtos comercias em tão larga escala como atualmente e que, assim sendo, o risco de alcançarem os diferentes compartimentos ambientais (atmosfera, águas e solo) e se tornarem disponíveis é muito grande..$^{21,22}$ 
Alguns estudos sugerem que os nanomateriais, por sua pequena dimensão, podem ter uma permeabilidade maior através da pele, mucosas e membranas celulares, podendo ter seu efeito tóxico magnificado, já que possuem uma reatividade superior, principalmente devido ao aumento da área superficial. Um exemplo clássico é o ouro, que é um metal praticamente inerte, mas que na forma de nanopartículas se torna altamente reativo. ${ }^{23}$

Outros fatores importantes a serem considerados no estudo da toxicidade dos nanomateriais são as várias formas como as partículas podem se apresentar após o contato com o ambiente ou organismos vivos, podendo estar presentes em sua forma livre assim como em aglomerados. Este processo é dinâmico e também pode ser acompanhado pela funcionalização da superfície destas por diferentes grupamentos químicos presentes no meio, como ácidos húmico e fúlvico. A Figura 1 ilustra os principais processos de alteração morfológica das nanopartículas no ambiente. ${ }^{24}$

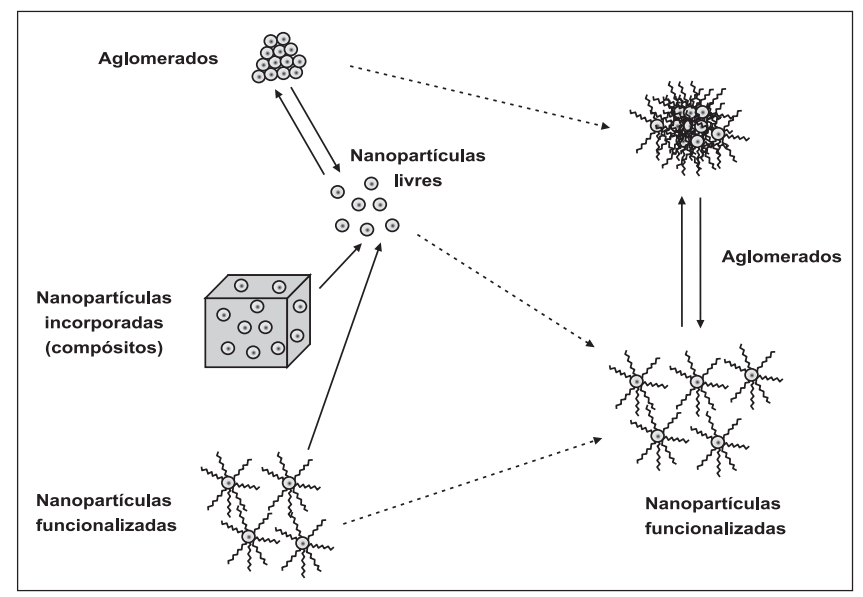

Figura 1. Principais fenômenos de modificação das nanopartículas quando em contato com o ambiente ou organismos vivos. Adaptado da ref. 24

\section{PRINCIPAIS FONTES DAS NANOPARTÍCULAS}

A identificação da fonte de emissão de nanopartículas é o primeiro passo para entender os fenômenos físicos e químicos associados às mesmas e assim relacioná-los com os possíveis efeitos ao ambiente e à saúde humana.

$\mathrm{O}$ aporte de nanopartículas no ambiente pode ser causado por fontes naturais e/ou antrópicas. Como exemplo de fonte natural temos o sal marinho e a poeira vulcânica, além de algumas moléculas como a magnetita biogênica e a proteína ferritina, de aproximadamente 12 $\mathrm{nm}$, que são encontradas no interior de organismos primitivos..$^{25,26} \mathrm{As}$ fontes denominadas antrópicas estão principalmente relacionadas aos processos industriais ou atividades que envolvem a queima de combustíveis fósseis e geram grande quantidade de material particulado. Desta forma, é importante discernir entre dois tipos de nanopartículas provenientes de fontes antrópicas: nanopartículas engenheiradas, manufaturadas para incorporação em materiais (nanocompósitos e nanomateriais em geral) e, nanopartículas não-engenheiradas, provenientes principalmente da queima de combustíveis fósseis. ${ }^{1,15,25}$

As principais fontes de nanopartículas não-engenheiradas envolvem atividades comuns, como cozinhar, e são importantes geradoras de nanopartículas inaláveis, onde a exposição a altas concentrações ocorre principalmente em ambientes confinados. Tais ambientes, por possuírem baixas taxas de renovação do ar, acabam por concentrar estas partículas, podendo proporcionar concentrações da ordem de 100.000 a 270.000 partículas $\mathrm{cm}^{-3} \cdot{ }^{27}$ Os gases provenientes da exaustão de escapamentos de veículos e outros processos de queima são as principais fontes urbanas de material particulado $\mathrm{PM}_{25}$ e nanomateriais, sendo identificados em vários estudos epidemiológicos como causadores de diversos efeitos nocivos à saúde, como doenças cardiorrespiratórias. ${ }^{28}$

Levando em consideração a gama de produtos à base de nanomateriais engenheirados disponíveis no mercado (cerca de 900), estes podem ser considerados, na atualidade, como a principal fonte de aporte destes materiais no ambiente ${ }^{29} \mathrm{e}$, por esta razão, a devida atenção deve ser dada ao seu processo de manufatura, transporte, armazenamento e descarte. Dentre os principais nanomateriais estão os orgânicos, como os nanotubos de carbono, os metálicos (principalmente óxidos de metais) e os pontos quânticos (quantum dots), como os nanomarcadores biológicos. Sob a ótica da aplicação para os mais variados fins e dos efeitos que tais materiais podem causar ao ambiente, destacam-se:

\section{Cosméticos}

A principal aplicação dos nanomateriais na área dos cosméticos são os protetores solares, nos quais o diâmetro das nanopartículas utilizadas é de aproximadamente $10 \mathrm{~nm}$. Estima-se que no biênio 2003/2004, a produção global de nanomateriais voltados para protetores solares foi de aproximadamente 1.000 toneladas, consistindo principalmente de nanopartículas de $\mathrm{TiO}_{2}(14 \mathrm{~nm})$ e $\mathrm{ZnO}(30-200 \mathrm{~nm})$. Estes óxidos são usados principalmente por absorverem a radiação ultravioleta (UV) nociva à pele humana, e que para constituírem uma emulsão transparente, devem apresentar dimensões nanométricas. $\mathrm{O}$ ambiente aquático seria o mais afetado por nanopartículas provenientes destes cosméticos, enquanto que a síntese e manipulação destes seria bastante prejudicial para a qualidade do ar. ${ }^{30}$

Outra aplicação muito comum em cosméticos são as nanoemulsões, que são uma combinação dos ingredientes tradicionais de cosméticos, como água, óleo, e surfactantes, que através de métodos específicos produzem nanopartículas com fases externa/interna distintas no que se refere à polaridade. Estas nanoemulsões produzem características ópticas, táteis e de textura ideais para cosméticos com boa aceitação do consumidor. ${ }^{30}$

\section{Nanomateriais de carbono}

Os nanomateriais baseados em carbono, como os negro de fumo (carbon black), fulerenos, nanotubos de carbono de parede simples ou múltipla, nanopartículas de carbono e nanofibras, são atualmente os mais atrativos devido a suas diferentes formas. Sabe-se que nanopartículas provenientes da queima de combustível de aeronaves, as quais são constituídas principalmente por nanofibras de carbono, podem ter uma influência direta sobre fenômenos que ocorrem na estratosfera, podendo alterar o clima devido à absorção/reflexão da radiação solar, o ciclo de formação de nuvens e o processo de destruição de ozônio pela inclusão de uma área superficial ativa adicional. ${ }^{31,32}$

Um dos nanomateriais que tem sido empregado em larga escala na indústria de borracha e tintas na forma incorporada é o negro de fumo. Estudos estão sendo realizados a fim de avaliar o efeito nocivo do negro de fumo não incorporado (livre), principalmente devido à sua inalação, o que pode estar relacionado à inflamação pulmonar. ${ }^{33,34}$

A nanopartícula do terceiro alótropo do carbono, fulereno $\left(\mathrm{C}_{60}\right)$, é a mais pesquisada e produzida em grande escala atualmente. A empresa Frontier Carbon foi a primeira empresa do mundo a sintetizar nanofulereno em grandes quantidades, produzindo atualmente mais de $40 \mathrm{t} \mathrm{ano}^{-1}$ deste material. ${ }^{24}$ Partículas de nanofulereno (nano- $\mathrm{C}_{60}$ ) vêm sendo testadas para atuarem como sensores e catalisadores e, devido a sua estrutura única, podem também ser usadas para liberação controlada de fármacos ${ }^{17}$ Devido à elevada produção e a recente aplicação do material em produtos utilizados no cotidiano como 
baterias, cosméticos e lubrificantes, provavelmente este material já esteja atingindo o meio ambiente de alguma forma. O fulereno é insolúvel em água e lipossolúvel, o que pode aumentar sua bioacumulação. ${ }^{20,21,26}$ Em função disso, a maioria dos estudos toxicológicos com nanopartículas está sendo realizado com $\mathrm{C}_{60}$, sendo contraditórios os resultados obtidos por diferentes pesquisadores, principalmente em função da falta de padronização nos testes de toxicidade e/ou a falta de complementação das pesquisas com testes de carcinogenicidade.

Outro material que também está em ponto de ser produzido em grande escala são os nanotubos de carbono, que configuram os nanomateriais com a mais alta resistência mecânica já observada, bem como alta capilaridade, possuindo estrutura eletrônica única. Desde o seu surgimento, em 1991, têm sido realizados estudos de viabilidade das condições de purificação e isolamento, caracterização e manipulação. ${ }^{35}$ Sua rota de síntese encontra-se em fase de consolidação e potenciais aplicações dos nanotubos são extensas, incluindo dispositivos para armazenamento e conversão de energia, semicondutores, sensores, armazenamento de hidrogênio, aditivos para materiais poliméricos e suporte em processos catalíticos. ${ }^{36-38}$

Vários estudos apontam para a aplicação de nanotubos tanto na área ambiental quanto na biotecnologia, como exemplificado por Long et al., que usaram nanomateriais adsorventes para remoção de $\mathrm{NO}_{x}$ sob baixa pressão. Li et al. observaram alta eficiência de adsorção na remoção de chumbo em meio aquoso. ${ }^{37,38}$ Em função da sua estrutura, também estão sendo testados em aplicações medicinais como transportadores de fármacos, já sendo utilizados em telas planas, pneus, tecidos, entre outros. ${ }^{15}$

Uma preocupação adicional com estes materiais deve-se a sua similaridade estrutural com os asbestos, os quais podem causar câncer no pulmão. Aparentemente, a toxicidade dos nanomateriais de carbono está também relacionada com a presença de alguns grupos químicos em sua superfície, como carbonilas e carboxilas, além da morfologia das partículas. ${ }^{17}$

\section{Nanomateriais usados para descontaminação ambiental}

A aplicação de nanomateriais na descontaminação ambiental é decorrente da alta reatividade química apresentada por estes materiais. $\mathrm{O}$ fotocatalisador $\mathrm{TiO}_{2}$, principalmente na sua forma anatase, é o nanomaterial mais estudado para a fotodegradação de compostos orgânicos. ${ }^{39,40}$

Raramente nanomateriais são adicionados diretamente a meios fluidos contaminados, pois as partículas necessitam ser removidas antes do descarte do efluente, o que encarece o processo de descontaminação. Assim, estes nanomateriais são usados principalmente na forma suportada sobre diferentes superfícies como polímeros, vidros e metais. ${ }^{41,42}$ Por mais aderida que as partículas estejam, o risco do efluente carregar parte do catalisador durante o uso deve ser considerado, principalmente quando o meio em questão é aquoso.

No caso de remediação de solos, como o agente descontaminante tem de ser adicionado diretamente no meio, sua remoção é difícil, favorecendo o contato da biota com o material, além da possibilidade deste ser arrastado até as águas subterrâneas. Neste caso, os fotocatalisadores são pouco utilizados em função da sua necessidade de radiação, sendo as nanopartículas de ferro (Fe-nano) o material mais empregado neste meio, principalmente para diminuir a toxicidade de solos contaminados com cromo, pela redução de $\mathrm{Cr}^{6+}$ para $\mathrm{Cr}^{3+}$, bem como na redução de compostos organoclorados. ${ }^{8}$

\section{Nanomateriais usados para desinfecção}

Após extensivos estudos demonstrando a atividade fotocatalítica do $\mathrm{TiO}_{2}$, atualmente um grande número de pesquisas comprovam sua ação biocida, principalmente em trabalhos em fase aquosa, apesar de seu maior uso comercial ser em purificadores destinados à fase gasosa. ${ }^{43}$

Provavelmente o nanomaterial mais proeminente em aplicações comerciais no momento seja a nanoprata (Ag-nano). Devido a sua potente atividade bactericida, este material vem sendo incorporado em diferentes produtos comerciais na área médico-hospitalar, como tecidos e implantes, sapatos e tênis, recipientes para armazenamento de alimentos, máquinas de lavar roupas, aparelhos de ar condicionado e até em creme dental. Também pode ser encontrado em próteses ósseas, instrumentos cirúrgicos, dentre muitos outros. ${ }^{4} \mathrm{~A}$ prata em escala macroscópica não apresenta efeito nocivo ao ser humano, salvo em casos de exposição anormais. Estudos recentes demonstraram que estas partículas quando inaladas podem ser bioacumuladas no cérebro, e quando absorvidas pela pele podem ocasionar danos a estruturas celulares fundamentais, como as mitocôndrias. ${ }^{4}$

\section{Aplicações em nanomedicina}

Nesta área, a busca pelo diagnóstico mais preciso e a administração controlada de fármacos configura como objetivos relevantes na busca por novas tecnologias para a prevenção e tratamento de doenças oncológicas. Neste sentido, uma classe de novos materiais, na qual se destacam os pontos quânticos de sulfeto de cádmio luminescentes ${ }^{44}$ tem sido alvo de estudos que levam à compreensão da correlação entre sua estrutura e energia, ${ }^{45}$ sendo altamente estáveis para identificar antígenos em células vermelhas do sangue. ${ }^{46}$ Pontos quânticos de $\mathrm{CdTe} / \mathrm{CdS}$ também têm aplicação na fotônica, ${ }^{47}$ nas áreas de microeletrônica e biomarcadores fluorescentes, ${ }^{48}$ que possibilitam a liberação controlada de fármacos durante o tratamento clínico, melhorando o controle e a administração de drogas.

Os nanotubos e nanofulerenos, por apresentarem espaços internos vazios, também vêm sendo investigados como transportadores de fármacos. Além dos nanotubos constituídos por carbono, também são empregadas estruturas nanotubulares compostas por nitreto de boro e óxidos metálicos como o $\mathrm{TiO}_{2}{ }^{49}$ Estas estruturas podem ser preenchidas por combinações químicas, enzimas e metais nobres, proporcionando a este tipo de material aplicações como marcadores biológicos. ${ }^{50}$ Assim, a liberação de nanofármacos no ambiente pode ocorrer pela excreção dos pacientes que usaram tais medicamentos ou pelo processo de manufatura dos mesmos.

Pelo exposto, é possível considerar que o aporte de nanopartículas no ambiente pode ocorrer desde a manufatura dos mesmos até o seu descarte, seja de forma direta, ou indireta. A maneira como são aportados pode ser determinante para definir as rotas de exposição, mecanismos de entrada no receptor e o modo como são distribuídos através do mesmo.

\section{ROTAS DE EXPOSIÇÃO, ACESSO E DISTRIBUIÇÃO DOS NANOMATERIAIS NO AMBIENTE}

Estudos de toxicidade e de ecotoxicidade de partículas cujos componentes são atóxicos em escala macro ou microscópica tornaram-se necessários pela mudança radical das propriedades deste material quando em escala nano, como a rápida mobilidade no ambiente e nos organismos. As principais rotas de exposição de um nanomaterial no ambiente são através dos sistemas aquáticos, da atmosfera (troposfera), do solo e sedimento. Desta forma, as principais rotas de entrada dos nanomateriais nos organismos-receptores são:

\section{Absorção no nível celular}

Quando as nanopartículas alcançam as células, estas podem ser absorvidas através da membrana celular por diversos processos, como 
a endocitose, que consiste na invaginação da parede celular sobre a partícula até englobá-la totalmente, ${ }^{19,51}$ ou por outro processo proposto mais recentemente, que consiste na entrada destas partículas através de organelas denominadas de caveolae, as quais são uma série de lipídeos especializados na função de transportar partículas, sendo um dos mecanismos utilizados por vírus, de dimensões nanométricas, para adentrarem nas células..$^{52,53}$

A absorção de nanomateriais no nível celular pode ocorrer principalmente em ambientes aquáticos, durante a filtração que organismos aquáticos realizam da água para seu consumo, podendo interferir na sua fisiologia ou habilidade de se alimentar. ${ }^{15,54}$

Dentro da célula, as nanopartículas podem gerar espécies de oxigênio reativas como os radicais hidroxila $\left({ }^{\circ} \mathrm{OH}\right)$, provocando o chamado estresse oxidativo de algumas organelas celulares, o qual gera um desequilíbrio redox que supera a defesa antioxidante da célula, causando uma grave disfunção celular. ${ }^{55,56}$

Em culturas de células humanas, Yehia et al. ${ }^{51}$ concluíram que nanotubos de carbono de parede simples não apresentaram efeitos tóxicos para células epiteliais cultivadas. Auffan et al. ${ }^{19}$ também não observaram efeito tóxico de nanopartículas de maghemita $\left(\gamma-\mathrm{Fe}_{2} \mathrm{O}_{3}\right)$ suportada em diferentes materiais sobre fibroblastos da derme humana, atribuindo a ausência de efeito à forma suportada do óxido que permitiria menor contato com as células.

\section{Inalação}

Atualmente há um consenso de que o maior risco das nanopartículas para organismos terrestres é devido a sua inalação. ${ }^{15,18}$ Estudos clínicos com humanos, roedores e cultura de células pulmonares foram realizados recentemente, sendo que na maioria destes, algum efeito tóxico, como inflamação do pulmão, asma, obstrução crônica pulmonar ou morte foi observada, ${ }^{28,57}$ sendo estimado que de 50 a $80 \%$ da exposição humana a nanopartículas inaláveis seja provenientes de fontes internas. ${ }^{30}$

A preocupação com a inalação de nanopartículas é devido principalmente ao fato de que quanto menor a partícula, mais facilmente ela vence as barreiras naturais do aparelho respiratório, sendo depositadas e acumuladas nos alvéolos, responsáveis pela troca gasosa de $\mathrm{O}_{2}$ e $\mathrm{CO}_{2}$ com a corrente sanguínea. Alguns estudos mostram que a inalação de partículas de $\mathrm{TiO}_{2}$ da ordem de $20 \mathrm{~nm}$ podem causar uma grave inflamação pulmonar. ${ }^{58}$

Para simular o acesso de nanopartículas respiráveis à corrente sanguínea, partículas provenientes da queima de diesel foram administradas por via intravenosa em ratos por Nemmar et al.. ${ }^{28} \mathrm{Os}$ pesquisadores observaram uma reação inflamatória sistêmica caracterizada pelo aumento de monócitos e granulócitos e o decréscimo de glóbulos vermelhos e da concentração de hemoglobina.

Uma vez depositadas no epitélio pulmonar, em contraste com partículas de tamanho maior, as nanopartículas aparentaram se translocar para locais extrapulmonares atingindo outros órgãos por diferentes rotas e mecanismos. Um possível mecanismo seria a transcitose através do epitélio do trato respiratório acessando a corrente sanguínea diretamente ou transportada por linfócitos, resultando na distribuição das nanopartículas por todo o corpo. ${ }^{25,53}$ Segundo a USEPA (U.S. Environmental Protection Agency), mais de 60.000 mortes por ano são atribuídas à inalação de nanopartículas atmosféricas, sendo reportado que a contaminação através da respiração pode atingir outros órgãos como coração e cérebro. ${ }^{15}$

Estudos centrados na saúde ocupacional mostram que em laboratórios e indústrias fabricantes de nanomateriais, o risco de exposição a altas concentrações destas partículas é muito grande, sendo necessário um controle rigoroso da qualidade do ar durante as operações de síntese ao empacotamento destes..$^{15,59}$

\section{Ingestão}

A ingestão involuntária de nanopartículas pode ocorrer principalmente pelo consumo de água proveniente de aparelhos para purificação de água que usam nanomateriais filtrantes ou desinfetantes, além da ingestão de alimentos que tiveram contato prolongado com utensílios que contenham prata suportada, por exemplo. Apesar desta possibilidade, estudos consideram que a ingestão deve ser pequena em termos de massa. ${ }^{15}$

Outra possibilidade é a ingestão voluntária dos chamados imunorreforçadores que podem conter prata coloidal. A ingestão prolongada de nanoprata foi comprovadamente relacionada com a manifestação de argíria, que é uma rara doença diagnosticada em casos de abuso de ingestão de sais de prata, causando o escurecimento irreversível da pele. ${ }^{4}$

As nanopartículas de prata também podem afetar o fígado, que funciona como um primeiro bloqueio para as partículas absorvidas no sistema gastrointestinal, conforme reportado por Takenaka et al. ${ }^{60}$ que observaram um grande depósito de nanopartículas de prata em fígado de ratos, sendo também recentemente confirmada sua toxicidade para células deste órgão em um experimento in vitro. ${ }^{61}$

Federici et $a l .^{3}$ reportaram que a ingestão de $\mathrm{TiO}_{2}$ por peixes pode causar erosão do epitélio intestinal, enquanto que Zhang et $a l .^{62}$ observaram que peixes expostos a uma concentração de $10 \mathrm{mg}$ $\mathrm{L}^{-1}$ de $\mathrm{TiO}_{2}$ por 25 dias apresentaram bioacumulação do material. No entanto, os níveis encontrados nos músculos e guelras foram baixos, sugerindo uma maior adsorção superficial do que uma absorção interna pelos órgãos.

\section{Assimilação através de superfícies epiteliais externas}

A exposição de nanopartículas à pele pode ser intencional pelo uso de cosméticos ou não-intencional pelo contato involuntário durante processos de síntese e combustão. ${ }^{15}$ Muito pouco se sabe sobre a permeabilidade da pele a nanopartículas ou sobre a interação das células da epiderme com estas. A dificuldade principal está no método e na quantidade de amostras ou voluntários humanos necessários para uma resposta fidedigna. A maioria das pesquisas foi realizada pela indústria de cosméticos, a qual geralmente almeja que componentes ativos da fórmula penetrem mais profundamente na pele para que os resultados sejam mais eficientes e de ação mais rápida. ${ }^{4}$

O risco do contato dérmico baseia-se na hipótese de que nanopartículas possam atingir a corrente sanguínea e assim circularem por todo o organismo, sendo distribuídas para células e órgãos. Alguns estudos sugerem que os materiais vesiculares usados em cosméticos (50 a $5000 \mathrm{~nm}$ ) podem penetrar o estrato córneo humano, porém não atravessariam a parte viva da pele. ${ }^{30}$

A maioria das pesquisas se concentra nos óxidos insolúveis mais utilizados em cosméticos, $\mathrm{ZnO}$ e $\mathrm{TiO}_{2}$, sugerindo que nanopartículas insolúveis não tenderiam a penetrar na pele humana saudável. Os poucos estudos que informam a absorção destas partículas pela pele indicam que o folículo e a presença de pelos teriam papel importante nesta absorção, principalmente quando as partículas estiverem na forma de emulsão oleosa. ${ }^{63}$

Em peixes, a principal absorção de nanopartículas pode ocorrer pelas guelras, usadas para respiração. Estudos de toxicidade usando nanotubos de carbono indicaram que estes nanomateriais provocaram a inflamação destas e um aumento na produção de muco.,26 Já as nanopartículas de $\mathrm{TiO}_{2}$ causaram a diminuição da atividade da enzima ATPase nas guelras e intestino de peixes, ${ }^{3}$ o que também foi registrado por Griffit et al. ${ }^{64}$ que observaram lesões nas guelras dos organismos testados após contato com nanopartículas de cobre. A Figura 2 ilustra as principais fontes e rotas de exposição às nanopartículas, além de alguns processos de interação com o ambiente e organismos vivos. 


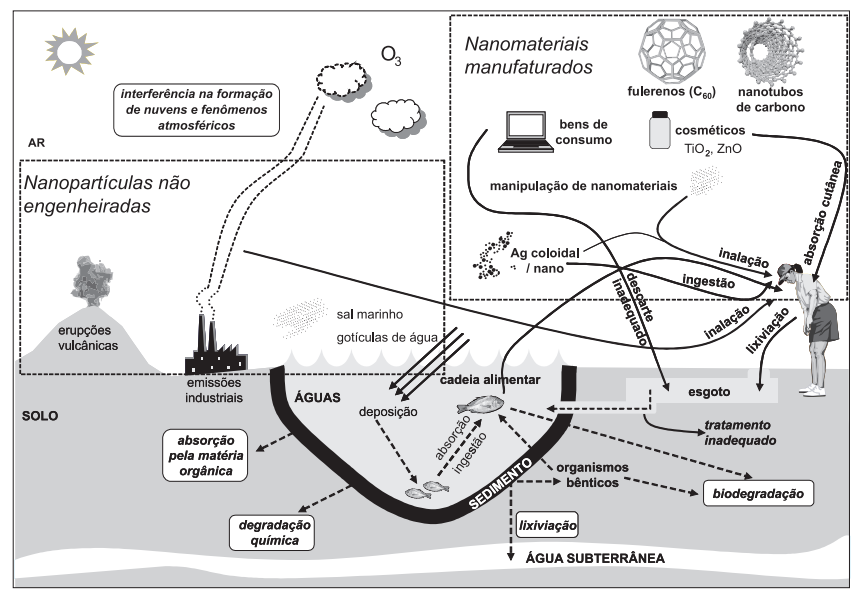

Figura 2. Principais fontes, rotas de exposição e processos de interação das nanopartículas com o ambiente e organismos vivos

A toxicidade do $\mathrm{TiO}_{2}$ sobre organismos aquáticos já foi testada com Daphnia magna e E. coli, mostrando que a geração de radicais reativos, quando iluminado por radiação UV ou solar, é um importante fator de risco desta partícula. ${ }^{65}$ Tong et al.,${ }^{16}$ ao monitorarem a atividade enzimática de uma comunidade microbiana em solo, observaram pequeno impacto quando da adição de fulereno de 1 a $1000 \mu \mathrm{g} \mathrm{C}_{60} \mathrm{~g}^{-1}$.

Uma possível rota de exposição direta às nanopartículas será a administração destas na corrente sanguínea, para avaliar como ocorre a distribuição de nanomateriais no organismo. Nanopartículas biocompatíveis, e que também possuem propriedades magnéticas, provavelmente serão usadas como agentes de contraste em exames de ressonância magnética. ${ }^{19}$

\section{TOXICOLOGIA DE NANOMATERIAIS}

Os estudos iniciais sobre a toxicidade de nanomateriais foram realizados na última década do século XX, investigando-se materiais que em escala micrométrica não apresentavam toxicidade, e que em escala nanométrica, como nanoparticulados, apresentavam algum efeito tóxico. Um dos primeiros trabalhos sobre esta temática foi realizado por Seaton et al. ${ }^{66}$ que, em um ensaio in vivo com ratos, observaram a inflamação de tecidos intersticiais somente dos indivíduos que foram expostos a partículas nanométricas de $20 \mathrm{~nm}$, enquanto que os demais, expostos a partículas de $250 \mathrm{~nm}$, mantiveram-se saudáveis.

Outro fator relacionado com partículas de dimensão nano- métrica é o fato destas não serem biologicamente inertes, como observado em 1996 por Donaldson et al., ${ }^{67}$ que testaram a atividade de $\mathrm{TiO}_{2}$ (25 e $500 \mathrm{~nm}$ de diâmetro) e constataram que a atividade biológica dos nanoparticulados de $25 \mathrm{~nm}$ foi muito superior a dos particulados de $500 \mathrm{~nm}$.

Com a crescente necessidade do conhecimento dos riscos potenciais dos compostos nanoestruturados diretamente relacionados à saúde humana surgiu o termo nanotoxicologia, que tem como objetivo estudar e avaliar a toxicidade de nanomateriais e nanodispositivos diretamente em contato com o homem. De forma análoga, o termo nanoecotoxicologia é utilizado para estudos voltados à avaliação dos efeitos de nanomateriais ao ambiente, ${ }^{68}$ elucidando os caminhos de transferência do agente tóxico, bem como sua interação com o mesmo. ${ }^{69}$ Tanto a nanotoxicologia quanto a nanoecotoxicologia, incluem a caracterização apropriada dos compostos investigados e os mecanismos de toxicidade dos mesmos, de modo que seus potenciais riscos sejam avaliados de forma segura. ${ }^{70}$

\section{CARACTERIZAÇÃO, QUANTIFICAÇÃO E AVALIAÇÃO DA TOXICIDADE DOS NANOMATERIAIS}

\section{Caracterização}

A caracterização adequada do nanomaterial é fundamental, já que a sua atividade biológica pode ser alterada radicalmente com a variação de algumas propriedades físico-químicas. Nesta caracterização, alguns parâmetros, tais como o tamanho médio das partículas, a área e a composição química superficial, são fundamentais. Quanto ao tamanho destas, o principal problema é que raramente uma partícula será encontrada no ambiente em sua forma primária e isolada, mas sim formando aglomerados que podem variar enormemente de tamanho (>100 nm) pela mudança das condições ambientais como força iônica e pH. ${ }^{15,71,72}$ Estes aglomerados são promovidos por forças relativamente fracas, tais como interações hidrofóbicas, mudando radicalmente o modo como são dispersos no ar e em fase aquosa, sendo este estado de dispersão uma das características mais difíceis de quantificar até então. ${ }^{73}$ Assim, uma tendência é o desenvolvimento e o aprimoramento de técnicas que permitam quantificar o tamanho dos agregados depois de dosados nos ensaios em fase aquosa e gasosa.

A Tabela 1 resume as principais técnicas utilizadas para determinar o tamanho, a área superficial e a composição de nanopartículas, assim como suas características morfológicas.

Embora não exista um protocolo para se determinar quais parâmetros físico-químicos são mais relevantes para serem medidos

Tabela 1. Principais técnicas usadas na caracterização de nanopartículas

\begin{tabular}{|c|c|c|}
\hline Técnica & Aplicação / Características & Ref. \\
\hline Difração de raios-X & Estrutura cristalina, tamanho da partícula & 71 \\
\hline Espalhamento dinâmico de luz & Tamanho de partículas (suspensão), distribuição por tamanhos & 79 \\
\hline Sedimentação por centrifugação & Distribuição dos tamanhos das partículas/complexo & 79 \\
\hline Cromatografia de exclusão por tamanho & Boa resolução, pequeno volume de amostra/lenta & 93 \\
\hline Microscopia de força atômica & Boa resolução/imagens 3D, só analisa a superfície & 93 \\
\hline Área superficial específica (BET) & $\begin{array}{c}\text { Tamanho das partículas, área superficial, simples, considera as partículas como } \\
\text { esferas monodispersas }\end{array}$ & 93 \\
\hline Microscopia eletrônica de varredura (MEV) & Morfologia da superfície, tamanho das partículas/boa resolução & 79 \\
\hline Microscopia eletrônica de transmissão (MET) & Estrutura local e morfologia & 93 \\
\hline Espectroscopia de energia dispersiva de raios-X (EDX) & Composição da superfície e mapeamento elementar & 93 \\
\hline Espectroscopia de fotoelétrons excitados por raios-X (XPS) & Análise química da superfície & 93 \\
\hline
\end{tabular}


em testes toxicológicos, é consenso, na maioria dos artigos que abordam a toxicidade de nanotubos de carbono, a necessidade do conhecimento do diâmetro e comprimento do material, além de sua pureza, que pode ser bastante alterada, principalmente de acordo com o catalisador utilizado.

Nos trabalhos com $\mathrm{TiO}_{2}$, as propriedades mais comumente descritas são o tamanho da partícula, calculada por DRX (Difração de Raios-X) e a área superficial, determinada pelo método BET (Brunauer-Emmet-Teller). ${ }^{14,18}$ Contudo, grande parte dos trabalhos da literatura não observa a capacidade das nanopartículas em formar aglomerados, o que seria fundamental em estudos sobre a translocação destas nos organismos.

\section{Quantificação de nanopartículas para estudos ecotoxicológicos}

Possivelmente o aspecto menos desenvolvido nos estudos toxicológicos são as técnicas para quantificação de nanomateriais no ambiente. Estes materiais, por possuírem características físico-químicas muito diferentes de seus precursores macroscópicos, necessitam do desenvolvimento de adaptações validadas das técnicas analíticas comumente empregadas. ${ }^{74,75}$

Poucos estudos realizam a quantificação do material após testes toxicológicos, já que normalmente a concentração inicial da nanopartícula adicionada é conhecida. No entanto, para estudos de bioacumulação, a quantificação dos materiais em diferentes órgãos do receptor necessita de técnicas específicas para cada tipo de material. Para nanofulereno, recentemente Isaacson et al. ${ }^{76}$ propuseram sua quantificação por cromatografia líquida acoplada à espectrometria de massas com ionização por electrospray (LC/ESI-MS) para estudos de toxicidade in vivo usando o peixe-zebra (Danio rerio). Para avaliar sua bioacumulação, o nano- $\mathrm{C}_{60}$ foi determinado tanto na suspensão utilizada quanto nos peixes.

\section{Testes de toxicidade}

Os testes de toxicidade podem ser realizados em culturas de células (in vitro) ou com organismos vivos (in vivo) como peixes, ratos e até seres humanos. Diversos ensaios toxicológicos padronizados estão disponíveis para se avaliar a resposta biológica de uma substância química. No entanto, não há padronização para a avaliação da toxicidade de nanopartículas, o que dificulta a comparação de resultados e o consenso sobre a toxicidade de um material. Os estudos realizados até o momento são adaptações dos procedimentos padrões utilizados para outras substâncias. ${ }^{8}$

A maioria dos testes de toxicidade de nanomateriais é realizada in vitro, usando culturas de células de mamíferos, as quais foram extraídas das mais diferentes partes do corpo como cérebro, pulmões, coração, pele e fígado..$^{28,55,77}$

Grande parte dos nanomateriais utilizados, como $\mathrm{TiO}_{2}$, nanotubos de carbono, nanoprata, e nano-FeO, foram testados para avaliar principalmente alterações na taxa de crescimento. ${ }^{19,51,55,78}$ Alguns trabalhos também realizaram sequenciamento de DNA para avaliar possíveis alterações genéticas, ${ }^{62}$ sendo as técnicas de microscopia eletrônica de varredura (MEV) e microscopia eletrônica de transmissão (MET) muito utilizadas neste tipo de ensaio para avaliar alterações morfológicas nas células ou a absorção das nanopartículas. ${ }^{65,79} \mathrm{~A}$ Tabela 2 apresenta algumas condições experimentais de ensaios in vitro com nanopartículas.

O maior uso das técnicas in vitro deve-se ao fato de que estas são muito menos onerosas do que estudos in vivo e requerem pouco tempo; no entanto, através delas é difícil inferir implicações que signifiquem riscos para saúde humana. Sayes et al. ${ }^{57}$ observaram pequena relação entre a toxicidade in vitro e in vivo, o que leva ao pressuposto de que os estudos in vivo são mais fidedignos na previsão dos efeitos reais em um dado organismo. Apesar disso, é consensual que este tipo de ensaio seja fundamental como etapa inicial de um estudo de toxicidade.

Em relação aos testes in vivo, observa-se que grande parte destes lança mão de organismos aquáticos, os quais traduziriam o impacto destes nanomateriais no ambiente, já que as águas continentais e marinhas seriam o principal compartimento receptor. Nestes testes normalmente são utilizados bactérias ( $V$. fischeri), peixes (peixezebra), crustáceos (Daphnia) e algas. ${ }^{20,59,76}$

Variando-se a concentração do nanomaterial em contato com os animais, o teste permite calcular estatisticamente os indicadores que irão possibilitar a comparação de toxicidade entre diferentes nanomateriais e/ou entre nanomateriais e substâncias químicas tradicionais. Os parâmetros de avaliação mais utilizados são o $\mathrm{LC}_{50}$, que é a concentração do nanomaterial que causa a morte de $50 \%$ da população, o LOEC, que é a menor concentração que provoca efeito observável no organismo, e o NOEC, que é a concentração máxima na qual nenhum efeito é observado nos organismos. ${ }^{15,21,59}$

Os principais testes in vivo que estão sendo usados atualmente para avaliação da ecotoxicidade de nanopartículas são os testes de toxicidade aguda. Estes ensaios, cujo objetivo é avaliar a toxicidade dos nanomateriais no meio aquático, estão sendo realizados principalmente com organismos do gênero Daphnia, como a Daphnia magna, que é um organismo-teste padrão da USEPA, em função de serem elos importantes na cadeia alimentar entre as algas, consumidas por estes, e os peixes, que são seus predadores. ${ }^{20}$

A maioria dos estudos de ecotoxicidade utilizou nanopartículas de $\mathrm{TiO}_{2}$ e $\mathrm{C}_{60}$, devido sua maior aplicação comercial. A comparação da toxicidade entre estes dois materiais pode levar a importantes elucidações sobre o impacto de diferentes partículas no ambiente já que estas possuem características físico-químicas muito distintas, tendo em vista o $\mathrm{TiO}_{2}$ ser hidrofílico e o nano- $\mathrm{C}_{60}$ lipofílico.

Em função de sua relativa simplicidade com relação a outras técnicas usando animais maiores, e em função de ser um organismo representativo já que sua extinção poderia causar grave desequilibro pela drástica diminuição de peixes, o teste com Daphnia provavelmente é o teste mais indicado no momento para avaliação da ecotoxicidade de nanomateriais, conforme mostra a tendência observada nos poucos trabalhos publicados. A Tabela 3 apresenta algumas condições experimentais empregadas em ensaios in vivo com nanopartículas.

Para animais de vida terrestre, além dos vários estudos in vitro, notase uma tendência para exposição direta de animais às nanopartículas, principalmente em mamíferos roedores. As técnicas mais utilizadas para exposição aos receptores, atualmente, são a administração intravascular e a inalação de nanopartículas por mamíferos.

Tabela 2. Tipos de células e condições experimentais usadas em alguns testes in vitro

\begin{tabular}{lccc}
\hline Nanomaterial & Diâmetro médio das partículas $(\mathrm{nm})$ & Concentração $\left(\mathrm{g} \mathrm{L}^{-1}\right)$ & Tipo de célula \\
\hline nano- $\gamma \mathrm{Fe}_{2} \mathrm{O}_{3}$ & 6 & $0-0,1$ & Fef. \\
$\mathrm{TiO}_{2} \mathrm{P}-25$ & 30 & $5-120$ & Fibroblastos (pele) \\
Poliestireno & 46 & 25 & Micróglias (cérebro) \\
Sílica & 50 & 0,5 & Células pulmonares \\
Nanotubo de carbono & $5-20$ & 50 & Células pulmonares \\
\hline
\end{tabular}


Tabela 3. Condições experimentais e valores de $\mathrm{LC}_{50}$ de alguns testes in vivo

\begin{tabular}{|c|c|c|c|c|c|}
\hline Nanomaterial & Diâmetro médio das partículas (nm) & Área superficial $\left(\mathrm{m}^{2} \mathrm{~g}^{-1}\right)$ & Organismo - teste & $\mathrm{LC}_{50}(48 \mathrm{~h})\left(\mathrm{mg} \mathrm{L}^{-1}\right)$ & Ref. \\
\hline Nano-Cu & $80-450$ & 30,8 & Peixe-zebra & 1,5 & 64 \\
\hline $\mathrm{C}_{60-}$ agitado & $10-200$ & - & Daphnia e peixe & 35 & 20 \\
\hline $\mathrm{C}_{60}-\mathrm{THF}$ & $10-200$ & - & Daphnia e peixe & 8 & 20 \\
\hline $\mathrm{C}_{60}$ & $100-450$ & - & Embrião de peixe-zebra & 0,13 & 76 \\
\hline $\mathrm{TiO}_{2}-$ filtrado & 30 & - & Daphnia & 5,5 & 54 \\
\hline $\mathrm{C}_{60}-$ sonicado & $20-100$ & - & Daphnia & 7,9 & 54 \\
\hline $\mathrm{C}_{60}-$ filtrado & $10-20$ & - & Daphnia & 0,46 & 54 \\
\hline
\end{tabular}

$\mathrm{THF}=$ Tetra-hidrofurano

Como a preocupação principal quanto à nanotecnologia é o provável acesso das nanopartículas ao sistema circulatório, alguns estudos já simulam tal situação injetando suspensões de nanopartículas diretamente na corrente sanguínea de ratos. ${ }^{4,28}$ Este tipo de teste provavelmente será uma tendência para a obtenção de respostas mais concretas sobre um risco agudo da exposição a cada tipo de nanopartícula. Nestes testes, ratos saudáveis e com massa semelhante recebem doses conhecidas de uma dada nanopartícula suspensa em algum líquido inócuo. Normalmente 48 $\mathrm{h}$ após a administração das partículas, amostras de sangue são coletadas para contagem de células, tais como monócitos, granulócitos, linfócitos, plaquetas, glóbulos vermelhos, além de medidas das concentrações de hemoglobina.$^{57}$ Este tipo de teste também pode ser usado para avaliar a provável distribuição e/ou bioacumulação de nanopartículas em órgãos vitais. Através deste procedimento, também é possível avaliar a distribuição do nanomaterial no organismo, o que é interessante para a indústria farmacêutica que pretende utilizar estes materiais como nanotransportadores.

A maioria dos estudos que busca correlacionar efeitos da inalação de nanopartículas foi realizado in vitro usando células de brônquios e alvéolos, ou in vivo injetando suspensão de nanopartículas na traquéia de ratos observando, em ambos, alterações relevantes no sistema respiratório. ${ }^{80} \mathrm{~A}$ tendência nos testes in vivo aponta para a simulação de atmosferas contaminadas, como descrito por Bermudez et al. que expuseram ratos e hamsters a um aerossol de $\mathrm{TiO}_{2}$ dentro de um recipiente selado, em condição de oxigenação normal, observando inflamação dos alvéolos. . $^{18,60}$

\section{REGULAMENTAÇÃO E PADRONIZAÇÃO DOS NANOMATERIAIS}

A regulamentação dos nanomateriais é imprescindível, pois até 2008, segundo dados do PEN (Project on Emerging Nanotechnologies) o número de produtos com algum componente nanométrico chegou a cerca de 800 , englobando produtos de higiene pessoal até meias bactericidas. ${ }^{29}$ Estima-se que até 2015 serão movimentados mundialmente cerca de US\$ 1 trilhão, e que todo o setor de semicondutores e metade do setor farmacêutico estará dependente destes novos materiais ${ }^{81}$ Sob a ótica dos potenciais riscos e perigos oriundos da expansão e desenvolvimento da nanotecnologia, tanto os Estados Unidos, quanto a União Europeia (UE), através de seus órgãos competentes, abarcaram as primeiras discussões para a avaliação de risco de nanomateriais, bem como a necessidade de futura implementação de regras e legislação específica aplicada a produtos que contenham em sua composição substâncias em nanoescala.

As primeiras iniciativas com o intuito de reunir informações sobre as áreas que precisam ser aprofundadas para avaliar os efeitos nocivos dos nanomateriais à saúde e ao ambiente foram realizadas pela Royal Society e a Royal Academy of Engineers e pelo NSCT americano (subcomitê do National Science and Technology Council). No Reino Unido, a Royal Society e a Royal Academy of Engineers publicaram em 2004 um estudo sobre os riscos ambientais à saúde, à segurança e as implicações éticas e sociais associadas ao desenvolvimento da nanotecnologia e as áreas onde a regulamentação deve ser considerada. ${ }^{8}$ Em julho de 2005, o NSCT emitiu o relatório "Environmental, health and safety research needs for engineered nanoscale materials" ${ }^{82}$ Com esta mesma preocupação, a agência de proteção ambiental americana, USEPA, lançou em 2008 um documento que trata dos benefícios, riscos e recomendações para o uso da nanotecnologia, devendo servir como instrumento de reflexão para o seu desenvolvimento. ${ }^{15}$

É de senso comum, tanto nos Estados Unidos, especialmente por meio da EPA, e na UE, principalmente pelas autoridades competentes para autorização de produtos, REACH CA (Registration, Evaluation, Authorisation \& restriction of CHemicals Competent Authorities), a falta de uma legislação que regulamente o uso de produtos manufaturados nanotecnologicamente. ${ }^{83,84} \mathrm{~A}$ fim de contribuir com o estágio atual de desenvolvimento e evolução da nanotecnologia, iniciativas estão sendo tomadas por distintos órgãos mundiais que têm como principais atribuições avaliar os riscos quanto à saúde humana e ao ambiente, além de instituir padrões para a produção e uso de novas tecnologias. Dentre estes órgãos destacam-se atualmente a USEPA, a Organização Mundial de Padronização, ISO (International Organization Standardization) e o REACH CA.

Para a regulamentação de um nanomaterial, a USEPA requer dos fabricantes evidências científicas de que o seu uso não causa danos ambientais e riscos à saúde pública. Uma saída para a questão da regulamentação seria adequar as normas já existentes para os produtos em escala nano. Esta seria uma decisão bastante crucial, uma vez que as propriedades de um determinado sistema condensado podem não ser as mesmas quando comparadas a um sistema em escala nano, como já foi discutido.

É importante destacar que os diferentes métodos de manufaturas de nanomateriais podem gerar produtos variados, com diferentes tipos e quantidades de impurezas, o que poderá refletir numa extensa variedade de resíduos. ${ }^{85}$ Desta forma, são necessários estudos específicos sobre o comportamento que cada tipo de nanomaterial apresenta quando se aloja nos inúmeros receptores ambientais ou nos seres humanos. ${ }^{8}$

Em 2008 foi lançado, também pela USEPA, o programa NMSP (Nanoscale Materials Stepwardship Program), que consiste primeiramente no cadastro voluntário de empresas de médio e grande porte que produzem e/ou comercializam nanomateriais com a finalidade principal de reunir informações sobre os mesmos. Até o momento cerca de 20 companhias aderiram, gerando um leque de 93 produtos já catalogados segundo suas especificações básicas (tais como o nome do nanomaterial empregado e o montante produzido), objetivando também obter dados sobre defeitos que o produto possa apresentar, potencial exposição e análise do ciclo de vida do nanomaterial presente. ${ }^{29}$ No sentido de formular uma regulamentação para os nanomateriais, a USEPA busca classificá- 
los como "substâncias químicas emergentes" e assim incluí-las no inventário da TSCA (Toxic Substances Control Act) caso não se insiram no inventário de substâncias químicas já conhecidas e avaliadas. ${ }^{83}$ Uma vez incluído no inventário da TSCA, o produto ou insumo passa por um procedimento específico que vai ditar as condições para a sua comercialização.

A certificação ISO para nanomateriais engloba a padronização de três aspectos fundamentais: a) terminologia e nomenclatura, b) caracterização e c) avaliação de risco sobre saúde, segurança e ambiente. Para tal foi elaborada a ISO/TC 229 (ISO/Technical Committee), que envolve um conjunto de ações e metas para viabilizar, através de grupos de trabalho representados por órgãos de metrologia e padronização de 36 países, a elaboração de protocolos padrão no período de 2005 a 2010 referentes aos três aspectos citados anteriormente. A ISO/TC 229 tem como um dos principais desafios uniformizar as definições a cerca do tema nanotecnologia e afins, de modo que as transações comerciais sejam as mais transparentes possíveis. Além disso, pretende estabelecer métodos precisos para a medição das propriedades dos nanomateriais, de modo que seja avaliada a qualidade do processo de produção, bem como estabelecer protocolos de utilização pelo consumidor. Participam efetivamente da ISO/TC 22920 países cada um com a sua representação específica, dentre eles Japão, Coreia, Estados Unidos e Brasil, cujo órgão responsável é o INMETRO (Instituto Nacional de Metrologia, Normalização e Qualidade Industrial). Outros 8 países, incluindo Argentina e Venezuela, participam como observadores. ${ }^{86}$

O material mais recente sobre regulamentação de nanomateriais foi publicado pela EU, através da REACH CA. Nesta organização, há um subgrupo de trabalho destinado a regulamentar a manufatura, importação, comercialização e o uso de nanomateriais, de forma a evitar impactos negativos à sociedade. De maneira geral, o sistema REACH abrange as etapas de registro, avaliação, autorização e restrições para a comercialização de uma substância em nanoescala, seja ela constituinte minoritário de uma matriz ou presente como componente majoritário.

$\mathrm{Na}$ etapa de registro, levam-se em conta informações a respeito de suas propriedades físico-químicas, usos, efeitos, forma de exposição, classificação e rotulagem, além da previsão dos possíveis cenários de exposição. Para realizar a etapa de avaliação de risco, o sistema REACH CA observa as orientações de estudos realizados pelo Comitê Científico Europeu para a Identificação de Riscos Emergentes à Saúde, SENIHR (Scientific Committee on Emerging and Newly Identified Heath Risks), que tem produzido documentos cujo enfoque é a discussão de mecanismos para que sejam desenvolvidos, validados e padronizados os procedimentos para estimar a exposição aos nanomateriais e a identificação de seus possíveis riscos. Essa questão foi abordada no último documento produzido pela SENIRH, em 2009, ${ }^{87}$ o qual trata da evolução da avaliação de risco de nanomateriais para a saúde humana e ao ambiente, englobando fatores como efeitos patogênicos, indução à genotoxicidade e efeitos de distribuição causados principalmente pelo tamanho das partículas e o potencial de bioacumulação na cadeia alimentar. Ainda na avaliação de substâncias em nanoescala, são estabelecidas regras quanto à fidedignidade das informações registradas, a fim de evitar especificações equivocadas sobre o material em questão. Já na etapa de autorização, a REACH CA segue os mesmos critérios de sustentabilidade econômica e ambiental aplicados às substâncias classificadas como substâncias tóxicas à reprodução, carcinogênicas ou mutagênicas, CRM (Carcinogenic, mutagenic or toxic for reproduction), e substâncias tóxicas, bioacumlativas e persistentes, PBT (Persistent, bioaccumulatiing and toxic). São aplicados critérios de controle de risco, envolvendo o descarte e/ou emissões (difusão ou dispersão), benefícios socioeconômicos, bem como conhecimento disponível dos riscos, que para os nanomateriais não se encontram consolidados e estabelecidos. Neste caso, dadas as propriedades únicas dos nanomateriais, quando os métodos aplicados aos CRMS e PBTS não se mostrarem adequados poderá, inevitavelmente, ocorrer uma mudança de paradigma quanto a sua avaliação de risco. Por fim, pelo escopo do REACH CA, as restrições são previstas no âmbito da manufatura, comercialização e descarte, quando causem riscos inaceitáveis à saúde humana e ao ambiente.

\section{CONSIDERAÇÕES FINAIS}

Dado o alto crescimento do número de produtos à base de nanomateriais em desenvolvimento e já comercializados, estima-se que o Brasil deverá compor uma fatia referente a $1 \%$ do mercado mundial neste segmento nos próximos anos, conforme estudo divulgado pelo Núcleo de Assuntos Estratégicos (NAE) da Presidência da República. ${ }^{81,88}$

Neste caso, com a ampla expansão na comercialização de produtos à base de nanomateriais engenheirados, o aporte destes materiais principalmente em ecossistemas aquáticos causaria desequilíbrios ainda maiores não apenas aos ecossistemas de países em desenvolvimento, como o Brasil, mas aos países desenvolvidos ou que são considerados subdesenvolvidos. De tal maneira que, conhecer e avaliar os riscos que os nanomateriais causam aos sistemas aquáticos é de fundamental importância, visto o agravamento de problemas mundiais quanto à escassez de água potável devido à poluição causada principalmente pela falta de tratamento de esgotos industriais e domésticos, o que gera graves problemas de saúde pública. ${ }^{89} \mathrm{O}$ lançamento de nanomateriais em sistemas de tratamento de esgotos convencionais, sem o conhecimento prévio do tratamento adequado para este tipo de resíduo, poderá causar perturbação no equilíbrio de todo o ecossistema aquático. ${ }^{90}$ Este se configura como um possível cenário observado, após o aporte de nanomateriais no ambiente. Contudo, uma análise mais elaborada e específica somente será possível mediante uma abordagem criteriosa da avaliação quanto à exposição e efeitos causados pelos mesmos.

De modo geral, os estudos toxicológicos envolvendo nanopartículas ainda são escassos, sendo seus resultados controversos quando comparados entre si, principalmente pela padronização incipiente. Os trabalhos são omissos principalmente na caracterização das partículas, contribuindo pouco na compreensão da interação destes no ambiente, tornando difícil a avaliação do real risco de exposição a estes materiais..$^{25,73,91,92}$ Apesar disso, a maioria dos estudos indica algum efeito tóxico agudo, o que demonstra a necessidade de um melhor entendimento dos efeitos destes materiais antes de serem utilizados em processos/produtos do cotidiano.

A análise de risco ambiental dos nanomateriais depende principalmente da estrutura regulatória, envolvendo a geração de protocolos, os quais devem ser baseados em uma interação multidisciplinar, principalmente entre a química, responsável pela síntese, quantificação e caracterização dos materiais, a biologia e a medicina, na concepção dos ensaios e na interpretação dos resultados a fim de se obter uma avaliação dos riscos do modo mais fidedigno possível.

Com o aumento das pesquisas nessa área, que abarquem o monitoramento ambiental de nanopartículas, será possível avaliar o risco de contaminação por estes materiais, através de cálculos probabilísticos. Deste modo, novas legislações devem surgir num futuro próximo indicando valores guia para cada nanomaterial e cada situação, além das novas tecnologias de tratamento para este tipo de resíduo.

$\mathrm{O}$ conhecimento dos riscos que os nanomateriais causam ao ambiente será importante para que a sua produção, comercialização e descarte sejam feitos de forma adequada e sustentável. Deste modo, visando a comercialização de produtos seguros, os mesmos deverão 
obedecer aos padrões exigidos pela legislação quanto aos aspectos ambientais e de saúde pública.

\section{AGRADECIMENTOS}

Aos revisores, pelos comentários pertinentes para o aprimoramento deste trabalho. À FAPESP (proc. 07/54699-4) a ao CNPq (proc. 142432/2006-7).

\section{REFERÊNCIAS}

1. Moore, M. N.; Environ. Int. 2006, 32, 967.

2. Smith, C. J.; Shawn, B. J.; Handy, R. D.; Aquat. Toxicol. 2007, 82, 94.

3. Federici, G.; Shawn, B.; Handy, R.; Aquat. Toxicol. 2007, 84, 415.

4. Chen, X.; Schluesener, H. J.; Toxicol. Lett. 2008, 176, 1.

5. Davies, J. C.; EPA and nanotechnology: oversight for the $21^{\text {ST }}$ century, Woordrow Wilson International Center for Scholars: Washington, D. C., 2007.

6. http://nanotecnologia.incubadora.fapesp.br/portal/referencias/ documentos/Relatorio\%20Nanotecnologia\%20Investimentos, \%20 Resultados\%20e\%20Demandas.pdf/view, acessada em Maio 2009.

7. http://lqes.iqm.unicamp.br/canal_cientifico/lqes_news/lqes_news_cit/ lqes_news_2008/lqes_news_novidades_1143.html, acessada em Maio 2009.

8. http://www.nanotec.org.uk/finalReport.htm, acessada em Maio 2009.

9. Seaton, A.; Donaldson, K.; The Lancet 2005, 18, 923.

10. Quina, F. H.; Quim. Nova 2004, 27, 1028.

11. ISI Web of Knowledge (SCI-EXPANDED); Topic $=(($ nanotechnology OR nanomaterials OR nanoparticles)) DocType $=$ articles; Language $=$ All languages; Timespan=1945-2009, results, acessada em Maio 2009.

12. ISI Web of Knowledge (SCI-EXPANDED); Topic $=($ nanotechnology OR nanomaterials OR nanoparticles) AND Topic $=$ (toxicity or toxicology) DocType $=$ articles; Language $=$ All languages; Timespan $=1945-2009$, results, acessada em Maio 2009.

13. http://www.redesecia.com.br/interface/doc/Artigo \% 20-\%20 Nanotecnologia.pdf, acessada em Maio 2009.

14. Song, W.; Li, G.; Grassian, V. H.; Larsen, S. C.; Environ. Sci. Technol. 2005, 39, 1214.

15. http://es.epa.gov/ncer/nano/publications/nano_strategy_012408.pdf, acessada em Maio 2009.

16. Tong, Z.; Bischoff, M.; Nies, L.; Applegate, B.; Turco, R. F.; Environ. Sci. Technol. 2007, 41, 2985.

17. Magrez, A.; Kasas, S.; Salicio, V.; Pasquier, N.; Seo, J. W.; Celio, M.; Catsicas, S.; Schwaller, B.; Forró, L.; Nano Lett. 2006, 6, 1121.

18. Bermudez, E.; Mangum, J. B.; Wong, B. A.; Asgharian, B.; Hext, P. M.; Warheit, D. B.; Everitt, J. I.; Toxicol. Sci. 2004, 77, 347.

19. Auffan, M.; Decome, L.; Rose, J.; Orsiere, T.; Meo, M.; Briois, V.; Chaneac, C.; Olivi, L.; Berge-Lefranc, J.; Botta, A.; Wiesner, M.; Bottero, J.; Environ. Sci. Technol. 2006, 40, 4367.

20. Oberdörster, E.; Zhu, S.; Blickley, T. M.; Mcclellan-Green, P.; Haasch. M. L.; Carbon 2006, 44, 1112.

21. Lovern, S. B.; Strickler, J. R.; Klaper, R.; Environ. Sci. Technol. 2007, $41,4465$.

22. Lyon, D. Y.; Adams, L. K.; Falkner, J. C.; Alvarez, P. J. J.; Environ. Sci. Technol. 2006, 40, 4360.

23. Service, R. F.; Science 2004, 304, 1732.

24. Farré, M.; Gajda-Schrantz, K.; Kantiani, L.; Barceló, D.; Anal. Bioanal. Chem. 2008, Nov, 6.

25. Oberdörster, G.; Oberdörster, E.; Oberdörster, J.; Environ. Health Perspect. 2005, 44, 1112.

26. Oberdörster, E.; Environ. Health Perspect. 2004, 112, 1058.

27. Afshari, A.; Matson, U.; Ekberg, L. E.; Indoor Air 2005, 15, 141.
28. Nemmar, A.; Inuwa, I. M.; Toxicol. Lett. 2008, 176, 20

29. Chatterjee, R.; Environ. Sci. Technol. 2008, 42, 7733.

30. Nohynek, G. J.; Lademann, J.; Ribaud, C.; Roberts, M. S.; Crit. Rev. Toxicol. 2007, 37, 251.

31. Han, H.; Chen, D.; Pui, D. Y. H.; Anderson, B. E.; J. Nanoparticle Res. 2000, 2, 43

32. Evelyn, A.; Mannick, S.; Sermon, P. A.; Nano Lett. 2003, 3, 63.

33. Donaldson, K.; Stone V.; Clouter, A.; Renwick, L.; MacNee, W.; Occup. Environ. Med. 2001, 58, 211.

34. Sager, T. M.; Castranova, V.; Part. Fibre Toxicol. 2009, 6, 15.

35. Iijima, S.; Nature 1991, 354, 56.

36. Herbst, M. H.; Macedo, M. I. F., Rocco, A. M.; Quim. Nova 2004, 27, 986.

37. Long, R. Q.; Yang, R. T.; Ind. Eng. Chem. Res. 2001, 40, 4288.

38. Li, Y. -H.; Wang, S.; Wei, J.; Zhang, X.; Xu, C.; Luan, Z.; Wu, D.; Wei, B.; Chem. Phys. Lett. 2002, 357, 263.

39. Chen, Y.; Crittenden, J. C.; Hackney, S.; Sutter, L.; Hand D. W.; Environ. Sci. Technol. 2005, 39, 1201.

40. Iketani, K.; Sun, R.; Toki, M.; Hirota, K.; Yamaguchi, O.; J. Phys. Chem. Solids 2003, 64, 507.

41. Guillard, C.; Beaugiraud, B.; Dutriez, C.; Herrmann, J.; Jaffrezic, H.; Jaffrezic-Renault, N.; Lacroix, M.; Appl. Catal. B 2002, 39, 331.

42. Li, G.; Qu, J.; Zhang, X.; Ge, J.; Water Res. 2006, 40, 213.

43. Kim, J.; Gonzalez-Martin, A.; McKenzie, S.; Kucera, S.; Abstracts - The Sixth International Conference on $\mathrm{TiO}_{2}$ Photocatalytic Purification and Treatment of Water and Air, Canada, 2001.

44. Zhang, K.; Chang, H.; Fu, A.; Alivisatos, A. P.; Yang, H.; Nano Lett. 2006, 6, 843 .

45. Farias, P. M. A.; Santos, B. S.; Longo, R. L.; Ferreira, R.; César, C. L.; Mater. Chem. Phys. 2005a, 89, 21.

46. Farias, P. M. A.; Santos, B. S.; Menezes, F. D.; Ferreira, R. D.; BarjasCastro, M. D.; Castro, V.; Lima, P. R. M.; Fontes, A.; Cesar, C. L.; J. Microscopy-oxford 2005b, 219,103.

47. Menezes, F. D.; Jr. Brasil, A. G.; Moreira, W. L.; Barbosa, L. C.; Cesar, C. L.; Ferreira, R. C.; Farias, P. M. A.; Santos, B. S.; Microelectron. J. 2005, 36, 989 .

48. Alivisatos, A. P.; J. Phys. Chem. 1996, 100, 13226.

49. Jitianu, A.; Cacciaguerra, T.; Berger, M.; Roland, B.; Béguin, F., Bonnamy, S.; J. Non-Cryst. Solids 2004, 345.

50. Xu, M.; Ma, J.; Gu, J.; Lu, Z.; Supramol. Sci. 1998, 5, 511.

51. Yehia, H. N.; Draper, R. K.; Mikoryak, C.; Walker, E. K.; Baja, P.; Musselman, I. H.; Daigrepont, M. C.; Dieckmann, G. R.; Pantano, P.; J. Nanobiotechnol. 2007, 5, 8 .

52. Shin, J.; Abraham, S. M.; Science 2001, 293, 1447.

53. Chen, C.; Xing, G.; Wang, J.; Zhao, Y.; Li, B.; Tang, J.; Jia, G.; Wang, T.; Sun, J.; Xing, Li.; Yuan, H.; Gao, Y.; Meng, H.; Chen, Z.; Zhao, F.; Chai, Z.; Fang, X.; Nano Lett. 2005, 5, 2050.

54. Lovern, S. B.; Klaper, R.; Environ. Toxicol. Chem. 2006, 25, 1132.

55. Long, T. C.; Saleh, N.; Tilton, R. D.; Lowry, G. V.; Veronesi, B.; Environ. Sci. Technol. 2006, 40, 4346.

56. Xia, T.; Kovochich, M.; Brant, J.; Hotze, M.; Sempf, J.; Oberley, T.; Sioutas, C.; Yeh, J. I.; Wiesner, M. R.; Nel, A. E.; Nano Lett. 2006, 6, 1794.

57. Sayes, C. M.; Reed, K. L.; Warheit, D. B.; Toxicol. Sci. 2007, 97, 163.

58. Suzuki, H.; Toyooka, T.; Ibuki, Y.; Environ. Sci. Technol. 2007, 41, 3018.

59. Hund-Rinke, K.; Simon, M.; Environ. Sci. Pollut. Res. 2006, 1, 1.

60. Takenaka, S.; Karg, E.; Roth, C.; Schulz, H.; Ziesenis, A.; Heinzmann, U.; Schramel, P.; Heyder, J.; Environ. Health Perspect. 2001, 4, 547.

61. Hussain, S. M.; Hess, K. L.; Gearhart, J. M.; Geiss, K.T.; Schlager J. J.; Toxicol. In vitro 2005, 19, 975.

62. Zhang, Z.; Yuan, Y.; Shi, G.; Fang, Y.; Liang, L.; Ding, H.; Jin, L.; Environ. Sci. Technol. 2007, 41, 6259.

63. Tsuji, J. S.; Maynard, A. D.; Howard, P. C.; James, J. T.; Lam, C.; Warheit, D. B.; Santamariak, A. B.; Toxicol. Sci. 2006, 89, 42. 
64. Griffitt, R. J.; Weil, R.; Hyndman, K. A.; Denslow, N. D.; Powers, K.; Taylor, D.; Barber, D. S.; Environ. Sci. Technol., 2007, 41, 8178.

65. Fortner, J. D.; Lyon, D. Y.; Sayes, C. M.; Boyd, A. M.; Falkner, J. C.; Hotze, E. M.; Alemany, L. B.; Tao, Y. J.; Guo, W.; Ausman, K. D.; Colvin, V. L.; Hughes, J. B.; Environ. Sci. Technol. 2005, 39, 4307.

66. Seaton, A.; MacNee, W.; Donaldson, K.; Godden, D.; The Lancet 1995, $345,177$.

67. Donaldson, K.; Beswich, P. H.; Gilmour, P. S.; Toxicol. Lett. 1996, 88, 293.

68. Scheringer, M.; Nat. Nanotechnol. 2008, 3, 322.

69. Azevedo, F. A.; Chasin, A. A. M.; As bases toxicológicas da ecotoxicologia, $1^{\text {a }}$ ed., Rima: São Carlos, 2003.

70. Kipen, H. M.; Laskin, D. L.; Am. J. Physiol. Lung. Cell. Mol. Physiol. 2005, 289, L696.

71. Limbach, L. K.; Li, Y.; Grass, R. N.; Brunner, T. J.; Hintermann, M. A.; Muller, M.; Gunther, D.; Stark, W. J.; Environ. Sci. Technol. 2005, 39, 9370.

72. Wörle-Knirsch, J. M.; Kern, K.; Schleh, C.; Adelhelm, C.; Feldmann, C.; Krug, H. F.; Environ. Sci. Technol. 2007, 41, 331.

73. Hyung, H.; Fortner, J. D.; Hughes, J. B.; Kim, J.; Environ. Sci. Technol. 2007, 41, 179

74. Kittelson, D. B.; J. Aerosol Sci. 1998, 29, 575.

75. Hassellov, M.; Readman, J. W.; Ranville, J. F.; Tiede, K.; Ecotoxicology 2008, 17, 344

76. Isaacson, C. W.; Usenko, C. Y.; Tanguay, R. L.; Field, J. A.; Anal. Chem. 2007, 79, 9091.

77. Vileno, B.; Lekka, M.; Sienkiewicz, A.; Jeney, S.; Stoessel, G.; Lekki, J.; Forró, L.; Stachura, Z.; Environ. Sci. Technol. 2007, 41, 5149.

78. Jin, Y.; Kannan, S.; Wu, M.; Zhao, J. X.; Chem. Res. Toxicol. 2007, 20, 1126.
79. Bootz, A.; Vogel, V.; Schubert, D.; Kreuter, J.; Eur. J. Pharm. Biopharm. 2004, 57, 369.

80. Geys, J.; Coenegrachts, L.; Vercammen, J.; Engelborghs, Y.; Nemmar, A.; Nemery, B.; Hoet, P. H. M.; Toxicol. Lett. 2006, 160, 218.

81. http://www2.cst.gov.uk/cst/news/Files/nano_review.pdf, acessada em Maio 2009

82. http://www.nano.gov/NNI_EHS_research_needs.pdf, acessada em Maio 2009.

83. http://www.epa.gov/oppt/nano/nmsp-inventorypaper.pdf, acessada em Maio 2009.

84. http://ec.europa.eu/environment/chemicals/reach/pdf/nanomaterials.pdf, acessada em Maio 2009

85. http://www.technologyreview.com/Nanotech/16068/page1/, acessada em Maio 2009.

86. http://isotc.iso.org/livelink/livelink?func=doc.Fetch \&nodeid=6507632, acessada em Maio 2009.

87. http://ec.europa.eu/health/ph_risk/committees/04_scenihr/docs/ scenihr_o_023.pdf, acessada em Maio 2009.

88. http://www.nae.gov.br/cadernos_nae/12estudo_nanotecnologia.pdf, acessada em Maio 2009.

89. Rocha, J. C.; Rosa, A. H.,;Cardoso, A. A.; Introdução à química ambiental, $1^{\mathrm{a}}$ ed., Bookman: Porto Alegre, 2004.

90. Xing, Y.; Yang, X.; Dai, J.; J. Sol-Gel Sci. Technol. 2007, 43, 187.

91. Handy, R. D.; Kammer, F.; Lead, J. R.; Hassellov, M.; Owen, R.; Crane, M.; Ecotoxicology 2008, 17, 287.

92. Handy, R. D.; Owen, R.; Valsami-Jones, E.; Ecotoxicology 2008, 17, 315.

93. Powers, K. W.; Brown, S. C.; Krishna, V. B.; Wasdo, S. C. Moudgil, B. M.; Roberts, S. M.; Toxicol. Sci. 2006, 90, 296. 